Volume 10 Issue 2 (2021) Pages 182-205

Ta'dib: Jurnal Pendidikan Islam

ISSN: 2528-5092 (Online) 1411-8173 (Print)

https://ejournal.unisba.ac.id/index.php/tadib/article/view/8613

\title{
RESILIENCE AS MEDIATOR IN THE RELATIONSHIP BETWEEN PROACTIVE PERSONALITY AND CAREER ADAPTABILITY AMONG VOCATIONAL SCHOOL STUDENTS DURING COVID-19
}

\author{
Evi Luthfiyah Nurjamil, Wahyu Indianti \\ Magister Profesi Psikologi, Universitas Indonesia, Depok, Indonesia ${ }^{1,2}$ \\ DOI: https://doi.org/ 10.29313/tipi.v10i2.8613
}

\begin{abstract}
Abstrak
Pandemi COVID-19 telah mengurangi 2,3 juta peluang lapangan pekerjaan di Indonesia. Karir siswa SMK dinilai terancam karena lulusannya menyumbang tingkat pengangguran tertinggi di Indonesia, sehingga perlu ada usaha penyesuaian diri dalam merencanakan karir di masa depan. Penelitian ini menegakkan asumsi agar memiliki adaptabilitas karir yang kuat, siswa SMK perlu memiliki kepribadian proaktif yang mendorongnya untuk berinisiatif melakukan perubahan. Selanjutnya proses tersebut perlu dimediasi oleh kemampuan untuk bertahan menghadapi kesulitan (resiliensi). Penelitian ini dilakukan terhadap 686 orang siswa SMK di Indonesia menggunakan alat ukur Career Adapt-Abilities Scale International Form (CAAS-IF) untuk adaptabilitas karir, Proactive Personality Scale Short Form (PPS-SF) untuk kepribadian proaktif dan The Connor-Davidson Resilience Scale (CD-RISC) untuk resiliensi. Hasil pengujian menunjukkan bahwa kepribadian proaktif memiliki hubungan yang positif dan signifikan dengan adaptabilitas karir $\left(c^{\prime}=0,384, \mathrm{SE}=0,087, \mathrm{p}<0,001\right)$. Diketahui pula adanya efek mediasi secara parsial oleh resiliensi $\left(c^{\prime}=0,384<c=1,283\right)$. Penelitian ini dapat menjadi acuan pentingnya memperkuat layanan Bimbingan Karir yang memberikan informasi karir diluar bidang yang tersedia di SMK.
\end{abstract}

Kata Kunci: Adaptabilitas Karir; Kepribadian Proakif; Resiliensi; Siswa SMK.

Copyright (c) 2021 Evi Luthfiyah Nurjamil

$\triangle$ Corresponding author:

Email Address : evi.luthfiyah@ui.ac.id

Received: 12/10/2021. Accepted: 27/01/2022. Published: 28/01/2022. 


\section{PENDAHULUAN}

Era revolusi industri 4.0 ditandai dengan terjadinya otomatisasi, yakni meningkatnya peran teknologi dalam menggantikan pekerjaan manusia. Akibatnya, 23 juta lapangan pekerjaan di Indonesia terancam berkurang pada tahun 2030 mendatang (McKinsey \& Company, 2019). Berdasarkan penelitian yang dilakukan oleh The SMERU Research Institute (2020), pengurangan lapangan pekerjaan di Indonesia sudah mulai muncul di masa pandemi COVID-19 dengan menghilangnya 2,3 juta peluang lapangan pekerjaan. Keterbatasan lapangan pekerjaan tersebut memunculkan perubahan jumlah tingkat pengangguran terbuka (TPT) dari 4,9\% meningkat pada angka 6,2-6,7\%. Salah satu dampaknya mengancam lulusan Sekolah Menengah Kejuruan (SMK) yang seharusnya dapat langsung bekerja setelah lulus sekolah, ketika kondisi pandemi justru terancam menjadi pengangguran (Sagita, 2020).

Berdasarkan informasi dari Badan Pusat Statistik (BPS) pada tahun 2020 angka pengangguran di Indonesia dalam setahun terakhir bertambah hingga 60 ribu orang, dengan tingkat pengangguran tertinggi berasal dari lulusan SMK. Oleh karena itu, untuk mencegah bertambahnya pengangguran di tengah perkembangan Revolusi Industri 4.0 dan situasi pandemi, perlu adanya kesadaran pelajar untuk menambah keahlian sehingga dapat menjadi tenaga kerja yang profesional (Rezasyah, Darmawan \& Rifawan, 2019). Keahlian yang diperlukan dalam dunia industri, tidak hanya berkaitan dengan kemampuan teknis (hard skills) yang dipelajari di sekolah saja, yakni kemampuan yang diasah berdasarkan konteks pelatihan untuk tujuan pekerjaan (Shivanjali, 2010). Bagi siswa SMK penting juga untuk menguasai serta meningkatkan soft skills, salah satunya terkait dengan keterampilan berkomunikasi, berinisiatif dan beradaptasi dengan lingkungan sekitarnya (Neff \& Citrin, 2001; Klaus, 2007).

Di tengah-tengah revolusi Industri 4.0, adaptasi dibutuhkan untuk memperkuat kualitas sumber daya manusia dalam negeri dan memperkuat daya saing sehingga dapat menyesuaikan diri dengan perubahan kebutuhan lapangan pekerjaan (Rezasyah, Darmawan and Rifawan, 2019). Disamping itu, kemampuan beradaptasi dengan mempersiapkan karir di masa depan bagi siswa SMK juga menjadi salah satu tugas perkembangannya di tahap remaja yakni menentukan karir masa depan (Santrock, 2012). Tuntutan tersebut mendorong siswa untuk memikirkan dan mempertimbangkan minat, kapasitas, dan nilai yang tepat untuk dapat memilih karir yang sesuai (Hirschi, 2009; Savickas, 2005; Sharf, 2006).

Peneliti mencoba menggali gambaran masalah siswa SMK dalam merencanakan karir melalui survey yang dilakukan terhadap 67 orang siswa SMK di Depok dan Jakarta. Hasil survei menunjukkan bahwa $80 \%$ siswa SMK memiliki tujuan utama untuk bekerja setelah lulus sekolah. Namun demikian ketika siswa SMK ditanya terkait perencanaan masa depan setelah lulus SMK, data menunjukkan bahwa hanya 56,7\% siswa yang berencana untuk bekerja. Ketika peneliti melakukan analisa data secara kualitatif, sebagian besar siswa masih merasa bingung atas pilihan yang akan diambilnya setelah lulus SMK. Meskipun saat awal masuk SMK memiliki tujuan awal untuk bekerja, siswa SMK merasa masih belum memiliki kesiapan untuk bersaing di dunia pekerjaan sehingga dianggap perlu melanjutkan sekolah kembali. Oleh karena itu, kompetensi yang penting dimiliki oleh siswa SMK agar memiliki kesiapan untuk menghadapi transisi ke dunia kerja yakni menciptakan strategi yang tepat untuk menyesuaikan diri dengan kondisi yang dihadapi dan menerapkan perilaku adaptif sesuai tujuan karir (Savickas \& Porfeli, 2012).

Kendala umum lainnya yang muncul berdasarkan hasil wawancara peneliti pada siswa SMK, ditemukan adanya masalah keterbatasan ekonomi dan pengaruh paksaan orang tua untuk masuk SMK. Namun demikian, masalah tersebut dapat teratasi jika siswa mampu beradaptasi di tengah keterbatasan dan tetap berusaha mengembangkan diri sesuai minat serta potensi yang dimiliki. Oleh karena itu dalam beradaptasi secara karir, siswa SMK perlu memperkuat kemampuan mengelola kendala eksternal baik terkait dengan kondisi pandemi ataupun tantangan lain agar dapat menentukan jalur karir yang tepat di tengah kondisi yang buruk. Kemampuan adaptabilitas karir di tengah pandemi dapat mengarahkan seseorang untuk menghadapi transisi dari situasi tertekan 
menuju kehidupan yang lebih bermakna, mempertahankan integritas, meningkatkan rasa kemanusiaan dan kontinuitas diri menghadapi perubahan karir paska pandemi (Ramdhani \& Kiswanto, 2020).

\section{METODE PENELITIAN}

\section{Partisipan}

Populasi penelitian ini ditujukan pada tahap perkembangan remaja akhir yang menempuh pendidikan sebagai siswa Sekolah Menengah Kejuruan (SMK) dengan rentang usia sekitar 15-22 tahun (Santrock, 2012). Pada rentang usia ini juga remaja berada pada tahap eksplorasi karir yang membuat individu melewati proses kristalisasi dan spesifikasi karir (Super, dalam Betz \& Voyten, 1997). Adapun pemilihan partisipan penelitian ini melibatkan teknik convenience sampling yang termasuk ke dalam non-probability sampling (Cozby \& Bates, 2012). Teknik ini diambil ketika jumlah populasi tidak diketahui dengan pasti dan sebagai pertimbangan kemudahan serta untuk menghindari bias. Adapun karakteristik partisipan penelitian ini adalah remaja berusia sekitar 1522 tahun dengan batasan usia pada tahap perkembangan remaja madya yang mana menurut Gunarsa \& Gunarsa (2001) setingkat dengan siswa Sekolah Menengah Atas. Karakteristik lainnya yakni partisipan tengah menempuh pendidikan sebagai siswa SMK dan masih terdata sebagai siswa aktif di Indonesia.

\section{Desain}

Penelitian ini menggunakan model penelitian kuantitatif dan jenis penelitian noneksperimental dengan desain metode korelasional. Artinya, tidak ada proses manipulasi terhadap variabel penelitian. Peneliti menguji hipotesis terhadap hubungan kepribadian proaktif dengan adaptabilitas karir serta efek mediasi resiliensi terhadap hubungan antara dua variabel tersebut pada siswa SMK.

\section{Prosedur}

Peneliti memulai tahap persiapan dengan melakukan survey terhadap 67 siswa SMK di Jakarta dan sekitarnya untuk mendapatkan gambaran terkait permasalahan siswa SMK dan penyesuaian diri siswa terhadap karir masa depannya. Setelah mempersiapkan alat ukur, peneliti melakukan tahap uji keterbacaan dan expert judgement untuk mendapatkan saran perbaikan terkait alat ukur yang akan dilakukan uji coba. Setelah dilakukan revisi, pada tahap uji coba peneliti melakukan pengambilan data terhadap 100 orang partisipan yang masih berstatus siswa aktif salah satu SMK di Indonesia dengan menggunakan kuesioner online. Peneliti menemukan adanya nilai validitas dan reliabilitas yang tinggi pada masing-masing alat uku (Tabel 1). Namun demikian, pada alat ukur resiliensi ditemukan adanya 4 item yang memiliki validitas rendah, sehingga peneliti melakukan revisi item untuk kemudian digunakan dalam proses pengumpulan data (Tabel 2). Secara keseluruhan total partisipan penelitian yang mengisi kuesioner sebanyak 761 orang, namun setelah peneliti melakukan proses data cleaning yakni mengidentifikasi duplicate case dan eliminasi responden yang tidak sesuai kriteria, diperoleh total partisipan sebanyak 686 orang.

Tabel 1. Hasil Uji Reliabilitas dan Validitas

\begin{tabular}{lll}
\hline Alat Ukur & $\begin{array}{l}\text { Alpha } \\
\text { Cronbach }\end{array}$ & $r_{i t}$ \\
\hline $\begin{array}{l}\text { Adaptabilitas } \\
\text { Karir }\end{array}$ & 0,934 & $0,387-0,687$ \\
\hline $\begin{array}{l}\text { Kepribadian } \\
\text { Proaktif }\end{array}$ & 0,855 & $0,457-0,660$ \\
\hline Resiliensi & 0,902 & $0,203-0,632$ \\
\hline
\end{tabular}


Tabel 2. Hasil Uji Reliabilitas dan Validitas

\begin{tabular}{|c|c|c|}
\hline Item & Item Uji Coba & Item Revisi \\
\hline 3 & $\begin{array}{l}\text { Saya meyakini takdir atau } \\
\text { pertolongan Tuhan dapat } \\
\text { membantu saya }\end{array}$ & $\begin{array}{l}\text { Saya meyakini bahwa } \\
\text { pertolongan Tuhan dapat } \\
\text { membantu saya }\end{array}$ \\
\hline 9 & $\begin{array}{l}\text { Saya percaya selalu ada alasan } \\
\text { di balik sebuah kejadian }\end{array}$ & $\begin{array}{l}\text { Selalu ada alasan di balik } \\
\text { sebuah kejadian }\end{array}$ \\
\hline 20 & $\begin{array}{l}\text { Terkadang saat menghadapi } \\
\text { masalah, saya bertindak sesuai } \\
\text { intuisi (firasat) tanpa } \\
\text { memikirkan alasannya }\end{array}$ & $\begin{array}{l}\text { Dalam menghadapi masalah, } \\
\text { saya mengandalkan intuisi } \\
\text { (firasat) }\end{array}$ \\
\hline 25 & $\begin{array}{l}\text { Saya bangga atas prestasi yang } \\
\text { telah saya raih }\end{array}$ & $\begin{array}{l}\text { Saya menghargai prestasi yang } \\
\text { telah saya raih }\end{array}$ \\
\hline 26 & $\begin{array}{l}\text { Saya meyakini takdir atau } \\
\text { pertolongan Tuhan dapat } \\
\text { membantu saya }\end{array}$ & $\begin{array}{l}\text { Saya percaya adanya takdir } \\
\text { dalam kehidupan }\end{array}$ \\
\hline
\end{tabular}

\section{Instrumen}

Peneliti menggunakan alat ukur Career Adapt-Abilities Scale International Form (CAAS) dari Savickas \& Porfeli (2012). Alat ukur ini telah diadaptasi oleh Gunawan (2013) untuk meneliti adaptabilitas karir siswa SMA yang berada pada tahap perkembangan remaja usia 15-24 tahun. Sementara itu, alat ukur untuk kepribadian proaktif menggunakan Proactive Personality Scale Short Form (PPS-SF) dari Seibert, Crant \& Kraimer (1999). Alat ukur ini telah diadaptasi untuk remaja di tingkat SMA dan SMK (Preston, 2018; Fatin, 2020). Sedangkan alat ukur resiliensi yang digunakan adalah The Connor-Davidson Resilience Scale (CD-RISC) dari Connor \& Davidson (2003). Alat ukur ini telah diadaptasi oleh Hamidi (2017) ke dalam Bahasa Indonesia untuk digunakan pada mahasiswa.

\section{Teknik. Analisis}

Proses analisa data dilakukan dengan menguji reliabilitas dan validitas konstruk terlebih dahulu sebelum menggunakan model penelitiannya. Dalam uji reliabilitas dilakukan perhitungan dengan Alpha cronbach, setelah dilakukan validitas item selanjutnya mengolah data dengan program IBM SPSS Statistics 25 dan Hayes PROCESS v 3.5 for SPSS. Analisis model pengukuran yang digunakan untuk melihat gambaran menyeluruh mengenai peran kepribadian proaktif dan resiliensi terhadap adaptabilitas karir.

\section{HASIL DAN PEMBAHASAN}

Berdasarkan data demografis, dapat diketahui bahwa partisipan perempuan (49,6\%) dan lakilaki $(50,4 \%)$ yang mengikuti penelitian ini jumlahnya relatif seimbang. Sementara itu, usia partisipan dalam penelitian berusia 14-17 tahun (86,9\%) sesuai target peneliti. Adapun tingkat pendidikan SMK yang menjadi mayoritas partisipan berasal dari kelas 10 (36,3\%) dan kelas 12 (36,2\%). Domisili partisipan sebagian besar masih terfokus di Jawa Barat $(54,1 \%)$.

Saat siswa SMK diberikan pertanyaan terkait pengalaman praktek pekerjaan yang sesuai dengan bidangnya, mayoritas partisipan $(65,6 \%)$ menjawab belum pernah memiliki pengalaman kerja. Sementara itu, layanan bimbingan karir $(\mathrm{BK})$ di SMK Indonesia kehadirannya belum merata atau bahkan belum cukup dikenal oleh siswa SMK. Hal tersebut didasarkan pada proporsi antara jawaban siswa yang menyadari keberadaan layanan bimbingan karir $(55,2 \%)$ dibandingkan dengan siswa yang mengaku tidak ada atau tidak mengetahui layanan BK (44,7\%), perbedaannya relatif tidak signifikan. Berdasarkan perhitungan model penelitian menggunakan Hayes, diperoleh data adanya hubungan positif dan signifikan antara kepribadian proaktif dengan resiliensi $(a=1,420,<$ $0,001)$. 
Selain itu juga ditemukan hubungan positif yang signifikan antara resiliensi dan adaptabilitas karir $(\mathrm{b}=0,633,<0,001)$. Adapun terkait total effect telah ditemukan adanya signifikansi dalam model penelitian ( $c=1,283,<0,001$ ), sehingga dapat disimpulkan bahwa kepribadian proaktif mempengaruhi adaptabilitas karir secara positif dan signifikan. Hasil pengolahan data menunjukkan adanya hubungan yang positif dan signifikan antara kepribadian proaktif dan adaptabilitas karir (c' $=0,384, \mathrm{SE}=0,087, \mathrm{p}<0,001)$. Hal tersebut dapat diartikan dengan semakin tingginya kepribadian proaktif seseorang, maka akan semakin tinggi pula adaptabilitas karirnya. Pada setiap kenaikan satu unit skor kepribadian proaktif, akan diiringi juga dengan kenaikan sebesar 0,384 pada skor adaptabilitas karir. Oleh karena itu, dalam penelitian ini, hipotesis 1 dapat diterima.

Tabel 3. Indirect Effect Melalui Resiliensi

\begin{tabular}{llll}
\hline Effect & SE (boot) & LLCI & ULCI \\
\hline $\mathbf{0 , 8 9 9}$ & 0,079 & 0,747 & 1,060 \\
\hline
\end{tabular}

Tabel 4. Koefisien Terstandar Indirect Effect Melalui Resiliensi

\begin{tabular}{llll}
\hline Effect & SE (boot) & LLCI & ULCI \\
\hline $\mathbf{0 , 4 0 4}$ & 0,033 & 0,335 & 0,471 \\
\hline
\end{tabular}

Peneliti juga menemukan adanya pengaruh mediasi (tidak langsung) secara positif dan signifikan $(\mathrm{ab}=0,899)$. Meskipun demikian mediasi yang terjadi bersifat parsial jika didasarkan pada nilai c' < c $(0,384<1,283)$. Menurut Baron dan Kenny (1986), hasil tersebut dapat disimpulkan partially mediated. Berdasarkan hasil analisis dapat disimpulkan bahwa variabel resiliensi memediasi secara parsial hubungan antara kepribadian proaktif dengan adaptabilitas karir. Hal tersebut menunjukkan bahwa hipotesis 2 penelitian ini diterima.

Dari tabel 3 dapat diketahui bahwa bias corrected bootstrap CI indirect effect $(\mathrm{ab}=0,899)$ pada 1000 bootstrap sampel, diperoleh nilai true indirect effect dengan estimasi yang berkisar antara 0,747 1,060 pada 95\% confidence interval (CI). Karena nol tidak terkandung dalam CI dan berada pada rentang di atas nol, maka dapat disimpulkan bahwa indirect effect positif dan efek mediasi terdukung. Berdasarkan rumusan rasio indirect effect terhadap total effect oleh Hayes (2017), didapatkan rasio effect size indirect effect sebesar 0,404 (tabel 4). Jadi, 40,4\% pengaruh kepribadian proaktif terhadap adaptabilitas karir secara tidak langsung terjadi melalui resiliensi, sisanya 59,6\% dipengaruhi oleh variabel atau faktor lain diluar penelitian. Oleh karena itu, dapat disimpulkan meskipun peran resiliensi menjadi mediasi parsial, namun hubungan kepribadian proaktif dan adaptabilitas karir dapat meningkat signifikan dengan adanya peran mediasi dari resiliensi.

\section{PEMBAHASAN}

Hasil penelitian ini menunjukkan bahwa terdapat hubungan antara kepribadian proaktif dengan adaptabilitas karir yang positif dan signifikan pada siswa SMK. Artinya, semakin tinggi tingkat kepribadian proaktif siswa SMK, maka akan semakin tinggi pula adaptabilitas karirnya. Seseorang yang memiliki kepribadian proaktif tinggi digambarkan sebagai individu yang dapat memberikan kontribusi berupa prestasi yang kemudian membawa perubahan bagi lingkungannya (Bateman \& Crant, 1993). Pada remaja yang sangat proaktif cenderung lebih mampu menunjukkan perilaku proaktif dalam penilaian diri, memperoleh informasi karir, penetapan tujuan, pemecahan masalah serta perencanaan yang berorientasi pada masa depan (Darmayanti \& Salim, 2020). Suthar (2020) menjelaskan hal tersebut terjadi karena individu yang memiliki kepribadian proaktif terampil dalam menyesuaikan diri dengan lingkungan sekitarnya dan lebih bertanggung jawab terhadap pekerjaan dan karirnya. Sejalan dengan penjelasan faktor-faktor yang mempengaruhi adaptabilitas karir, Han \& Rojewski (2015) menyebutkan faktor kepribadian proaktif sebagai salah satu faktor yang dapat mengukur kemampuan adaptasi seseorang.

Hirschi dkk. (2013) menilai kepribadian proaktif sebagai salah satu indikator adaptasi, menunjukkan adanya sifat-sifat yang berhubungan secara positif dengan kemampuan beradaptasi 
karir. Seseorang dengan kepribadian proaktif unggul dalam mengamati keadaan dan melihat peluang secara cepat (identifying opportunities) untuk membuat perubahan yang konstruktif dibandingkan dengan orang lain (Bateman \& Crant, 1993). Sehingga, saat individu dengan kepribadian proaktif dihadapkan pada kebutuhan untuk beradaptasi secara karir, akan memiliki kecenderungan untuk berhasil mengumpulkan, menegosiasikan dan melakukan modifikasi terkait karir yang ditempuh (Bateman \& Crant, 1993; Seibert, Crant \& Kraimer, 1999). Dorongan untuk mengamati keadaan dan melihat peluang ini dalam adaptabilitas karir berkaitan dengan dimensi career curiosity yang diartikan sebagai keingintahuan yang mendorong seseorang untuk mencari pilihan dan informasi yang sesuai dan dapat membantunya dalam mengambil keputusan karir (Savickas \& Porfeli dalam Nye dkk, 2017).

Setelah ditelaah lebih lanjut, karakteristik showing initiative berupa penggerak atau pendorong perubahan dalam lingkungan dalam kepribadian proaktif juga diketahui bersinggungan dengan dimensi career control yang diartikan sebagai pengendalian. Kesamaan tersebut mengarahkan seseorang untuk termotivasi dan disiplin dalam membentuk diri dan lingkungan untuk mencapai tujuan karir mereka (Savickas \& Porfeli dalam Nye dkk, 2017). Keterkaitan kepribadian proaktif dengan adaptabilitas karir didukung juga oleh beberapa penelitian yang mengemukakan bahwa adaptasi dapat diukur dengan kepribadian proaktif (Savickas \& Porfeli, 2012; Rudolph, 2017). Penelitian-penelitian sebelumnya menunjukkan adanya hubungan positif dan signifikan antara kepribadian proaktif dengan adaptabilitas karir (Cai et al., 2015; Jiang, 2017; Ulfah \& Akmal; 2019). Hasil penelitian tersebut sejalan dengan penemuan peneliti yang menunjukkan bahwa kepribadian proaktif memiliki hubungan yang positif dan signifikan dengan adaptabilitas karir.

Pada salah satu penelitian terkait pengaruh kepribadian proaktif terhadap adaptabilitas karir, Jiang (2017) menggunakan variabel thriving at work sebagai mediator. Namun demikian, hasil penelitian menunjukkan adanya mediasi parsial, sehingga kemungkinan diperlukan mediator lain untuk melihat pengaruh kepribadian proaktif terhadap adaptabilitas karir. Oleh karena itu, berdasarkan saran dari Jiang (2017), peneliti menguji peran mediasi dari variabel resiliensi. Pada penelitian yang berbeda, resiliensi juga diketahui menjadi prediktor terkuat dalam mempengaruhi adaptabilitas karir seseorang diantara positive psychology trait lainnya (Buyukgoze-Kavas, 2016; Othman, dkk., 2018). Selain itu, resiliensi juga diketahui memiliki korelasi positif dengan kepribadian proaktif. Dimana seseorang yang memiliki kepribadian proaktif cenderung memiliki kemampuan untuk bertahan di tengah-tengah kesulitan mempersiapkan karirnya. (Botha, Coetzee \& Coetzee, 2015; Tamannaeifar \& Shahmirzaei, 2019). Resiliensi dapat menggambarkan mekanisme penanganan masalah seseorang saat menghadapi hambatan yang akan mendukung upaya adaptabilitas karir seseorang dengan kepribadian proaktif. Individu yang memiliki resiliensi tinggi mampu memberikan respon yang sehat dan produktif dalam menghadapi setiap permasalahan sehingga tidak melukai diri sendiri ataupun orang lain. Kemampuan tersebut dapat diartikan sebagai kapasitas seseorang dalam mengatasi stress dengan optimal (Reivich \& Shatte, 2002).

Namun demikian, setelah dilakukan pengujian, peneliti menemukan bahwa peran mediator dari resiliensi terhadap hubungan antara kepribadian proaktif dengan adaptabilitas karir ternyata bukan merupakan mediator penuh. Hal tersebut dikarenakan dimensi resiliensi bersinggungan dengan salah satu dimensi dalam adaptabilitas karir. Hal tersebut tercermin dari kemampuan mengembangkan strategi ketika beradaptasi menghadapi perubahan (adaptability to change) yang menjadi bagian dari karakteristik resiliensi (Rutter dalam Connor \& Davidson, 2003). Karakteristik tersebut juga berkaitan dengan dimensi career confidence dalam adaptabilitas karir yang membuat seseorang yakin atas kemampuannya dalam mewujudkan cita-cita karirnya, sehingga memiliki kegigihan, daya juang, dan ketekunan dalam merencanakan dan mempersiapkan karir masa depan (Savickas, 2005; Savickas \& Porfeli dalam Nye dkk, 2017). Dimensi career control pada adaptabilitas karir yang mengarahkan individu untuk termotivasi dan disiplin, juga diketahui bersinggungan dengan karakteristik control dalam resiliensi yang mengarahkan pada sikap terencana dan mampu menentukkan arah hidupnya dengan jelas secara mandiri (Kobasa dalam Connor \& Davidson, 2003). 
Penyebab terjadinya mediasi parsial diketahui juga karena adanya kaitan antara resiliensi dengan kepribadian proaktif. Dimana dalam resiliensi juga terdapat dimensi tolerance of negative affect, berupa perilaku bertahan dengan bangkit kembali, bernegosiasi, mengelola dan beradaptasi dengan sumber stress yang sudah terwakili oleh kepribadian proaktif (Lyons dalam Connor \& Davidson, 2003). Hal tersebut tercermin dalam salah satu indikator kepribadian proaktif, yakni dimensi bertahan hingga mencapai perubahan yang bermakna (persevering until change is affected), yang membuat seseorang bersungguh-sungguh untuk mencapai tujuan (Bateman \& Crant, 1993). Oleh karena itu dengan adanya keterkaitan tersebut semakin membuktikan bahwa resiliensi memediasi secara parsial hubungan antara kepribadian proaktif dengan adaptabilitas karir.

Hasil penelitian ini dapat dijadikan sebagai salah satu acuan untuk penelitian selanjutnya sehingga diketahui peran variabel lain yang dapat memediasi hubungan kepribadian proaktif dengan adaptabilitas karir, misalnya dengan mempertimbangkan variabel individu lainnya seperti komitmen atau identifikasi profesional dan kecerdasan emosional (Bimrose \& Hearne, 2012; Jiang, 2016 dalam Jiang, 2017). Disamping itu, berdasarkan hasil survey peran faktor lingkungan seperti dukungan sosial dari orang tua atau teman-teman dapat diteliti lebih lanjut. Dukungan sosial diketahui dapat menjadi prediktor yang kuat terhadap adaptasi karir baik berasal dari keluarga, sekolah, dan temanteman (Han \& Rojewski, 2015).

Penelitian ini memiliki keterbatasan dalam pengumpulan data, dimana sampel penelitian yang diperoleh dalam penelitian ini masih terfokus di daerah Jawa Barat. Disamping itu, pengumpulan data menggunakan kuesioner online dinilai memiliki kendala yang perlu dipertimbangkan, seperti kesulitan bagi peneliti untuk mengontrol kondisi lingkungan saat siswa SMK mengisi kuesioner. Peneliti juga kurang mempertimbangkan aspek demografis, seperti jenis sekolah untuk melihat proporsi antara sekolah SMK negeri dan swasta yang memungkinkan siswa SMK memiliki perbedaan dalam memperoleh fasilitas layanan Bimbingan Konseling. Pengalaman kerja juga bisa menjadi salah satu pertimbangan dalam menetapkan karakteristik sampel, sebab seseorang yang memiliki pengalaman kerja sesuai minat dan bakat yang dimiliki relatif lebih mudah untuk mengeksplorasi karir dan mendapatkan informasi terkait karir dengan lebih terfokus dan mendalam (Mardiyati \& Yuniawati, 2015; Husna \& Mayangsari, 2017).

Dimensi spirituality dalam alat ukur resiliensi penelitian ini, diketahui memiliki nilai validitas yang rendah setelah dilakukan uji coba alat ukur. Namun demikian, setelah peneliti melakukan revisi dan diuji coba kembali, terdapat satu item yang validitasnya meningkat untuk mewakili dimensi tersebut. Oleh karena itu diperlukan penelitian lebih jauh untuk mengembangkan alat ukur resiliensi khususnya pada dimensi spirituality pada alat ukur CD-RISC versi 25 item. Selain itu, peneliti selanjutnya juga dapat menggunakan alat ukur CD-RISC 10 yang bersifat unidimensional. Alat ukur versi short form ini dinilai memiliki struktur faktor yang lebih baik, kuat, efisien dan ringkas dari alat ukur CD-RISC versi 25 item (Dolores et al, 2012; Goins et al., 2012; Gucciardi et al., 2011; NotarioPacheco et al., 2011; Burns \& Anstey 2010; Ye et al., 2017; Campbell-Sills \& Stein, 2007 dalam Salisu \& Hashim, 2017).

\section{KESIMPULAN}

Berdasarkan penelitian yang dilakukan terdapat dua kesimpulan untuk menjawab rumusan masalah. Pertama, ada hubungan positif yang signifikan antara kepribadian proaktif dan adaptabilitas karir pada siswa SMK di Indonesia. Kedua, resiliensi memediasi secara parsial hubungan antara kepribadian proaktif dengan adaptabilitas karir siswa SMK di Indonesia.

Saran metodologis untuk penelitian selanjutnya diharapkan dapat lebih mempertimbangkan proporsi pengambilan sampel agar tidak terfokus di daerah Jawa Barat saja jika pengambilan data dilakukan untuk skala se-Indonesia. Kontrol yang lebih ketat pada pengumpulan data online dapat dilakukan dengan mengaktifkan tools pembatasan satu tanggapan pada setiap responden. Pengaturan tersebut untuk mencegah terjadinya duplicate case. Peneliti selanjutnya dapat menambahkan data demografis dan variabel seperti jenis sekolah untuk melihat proporsi antara 
sekolah SMK negeri dan swasta, data latar belakang budaya, agama, sosial ekonomi dan lain-lain. Sehingga diharapkan dapat memunculkan gambaran yang lebih komprehensif dalam menjelaskan hubungan antara kepribadian proaktif dengan adaptabilitas karir pada siswa SMK. Dalam mengembangkan alat ukur resiliensi ini, peneliti selanjutnya disarankan menggunakan alat ukur CDRISC SF yang dikembangkan Campbell-Sills dan Stein (2007). Alat ukur ini bersifat unidimensional dimana pada beberapa penelitian terakhir memiliki validitas dan reliabilitas lebih baik dari CD-RISC versi asli (Salisu \& Hashim, 2017).

Hasil penelitian ini juga dapat dimanfaatkan oleh konselor atau siswa SMK untuk memperoleh pemahaman mengenai pentingnya merencanakan karir. Prosesnya dapat dimulai dari sikap inisiatif dalam mengeksplorasi diri dan lingkungan yang disertai dengan pengembangan strategi dalam mengelola stress saat menghadapi kesulitan beradaptasi mencapai tujuan. Pihak institusi pendidikan SMK, diharapkan dapat memfasilitasi siswa untuk meningkatkan adaptabilitas karir mereka setelah lulus dengan memperkuat program bimbingan karir. Pihak sekolah dapat memberikan kesempatan bagi siswa untuk mencari tahu bidang pekerjaan ataupun pendidikan yang sesuai dengan kapasitas dan minat yang dimilikinya meskipun bidang tersebut tidak berkaitan dengan jurusan yang dipilih oleh siswa.

\section{DAFTAR PUSTAKA}

Baron, R., \& Kenny, D. (1986). The moderator-mediator variable distinction in social psychological research: Conceptual, strategic, and statistical considerations. Journal of Personality And Social Psychology, 51(6), 1173-1182. https://doi.org/10.1037/0022-3514.51.6.1173

Badan Pusat Statistik. (2020, Mei 5). Berita Resmi Statistik. https://www.bps.go.id/website/materi ind/materiBrsInd-20200505115439.pdf

Bateman, T., \& Crant, J. (1993). The proactive component of organizational behavior: A measure and correlates. Journal of Organizational Behavior, 14(2), 103-118. https://doi.org/10.1002/job.4030140202

Bakker, A., Petrou, P., \& Tsaousis, I. (2012). Inequity in work and intimate relationships: a Spillover-Crossover model. Anxiety, Stress \& Coping, 25(5), 491-506. https://doi.org/10.1080/10615806.2011.619259

Betz, N., \& Voyten, K. (1997). Efficacy and Outcome Expectations Influence Career Exploration and Decidedness. The Career Development Quarterly, 46(2), 179-189. https://doi.org/10.1002/i.2161-0045.1997.tb01004.x

Botha, J., Coetzee, M., \& Coetzee, M. (2015). Exploring adult learners' self-directedness in relation to their employability attributes in open distance learning. Journal of Psychology in Africa, 25(1), 65-72. https://doi.org/10.1080/14330237.2015.1007603

Buyukgoze-Kavas, A. (2016). Predicting Career Adaptability From Positive Psychological Traits. The Career Development Quarterly, 64(2), 114-125. https://doi.org/10.1002/cdq.12045

Cai, Z., Guan, Y., Li, H., Shi, W., Guo, K., \& Liu, Y. et al. (2015). Self-esteem and proactive personality as predictors of future work self and career adaptability: An examination of mediating and moderating processes. Journal of Vocational Behavior, 86, 86-94. https://doi.org/10.1016/j.jvb.2014.10.004

Campbell-Sills L \& Stein MB (2007). Psychometric analysis and refinement of the ConnorDavidson Resilience Scale (CD RISC): Validation of a 10-item measure of resilience. Journal of Traumatic Stress, 20, 1019-1028. https://doi.org/10.1002/its.20271

Crant, J. (2000). Proactive Behavior in Organizations. Journal of Management, 26(3), 435-462. https://doi.org/10.1177/014920630002600304 
Cozby, P. C., \& Bates, S. (2012). Methods in behavioral research. McGraw-Hill.

Connor, K., \& Davidson, J. (2003). Development of a new resilience scale: The Connor-Davidson Resilience Scale (CD-RISC). Depression and Anxiety, 18(2), 76-82. https://doi.org/10.1002/da.10113

Darmayanti, K., \& Salim, R. (2020). The Enhanced Career Decision-Making Self-Efficacy by Emotional Intelligence Depended on Proactive Personality. Journal of Research in Educational Psychology, 18(1), 121-142.

Fatin, A. (2020). Emotional Intelligence, Career Decision Self-Efficacy, Proactive Personality: Study on Indonesian Vocational Students. Psychology and Education, 57(2), 91-94.

Gunarsa, S.D., dan Gunarsa, Y.S. (2001). Psikologi Praktis: Anak, Remaja dan Keluarga. BPK Gunung Mulia.

Hayes, A. (2017). Partial, conditional, and moderated moderated mediation: Quantification, inference, and interpretation. Communication Monographs, 85(1), 4-40. https://doi.org/10.1080/03637751.2017.1352100

Han, H., \& Rojewski, J. W. (2015). Gender-specific models of work-bound Korean adolescents' social supports and career adaptability on subsequent job satisfaction. Journal of Career Development, 42(2), 149-164. https://doi.org/10.1177\%2F0894845314545786

Hirschi, A. (2009). Career adaptability development in adolescence: Multiple predictors and effect on sense of power and life satisfaction. Journal of Vocational Behavior, 74(2), 145-155. https://doi.org/10.1016/i.jvb.2009.01.002

Hirschi, A., Lee, B., Porfeli, E. J., \& Vondracek, F. W. (2013). Proactive motivation and engagement in career behaviors: Investigating direct, mediated and moderated effects. Journal of Vocational Behavior, 83(1), 31-40. https://doi.org/10.1016/j.jvb.2013.02.003

Hou, C., Wu, L., \& Liu, Z. (2014). Effect of Proactive Personality and Decision-Making SelfEfficacy on Career Adaptability Among Chinese Graduates. Social Behavior and Personality: an International Journal, 42(6), 903-912. https://doi.org/10.2224/sbp.2014.42.6.903

Jiang, Z. (2017). Proactive personality and career adaptability: The role of thriving at work. Journal of Vocational Behavior, 98, 85-97. https://doi.org/10.1016/j.jvb.2016.10.003

Klaus, P. (2007). The hard truth about soft skills: Workplace lessons smart people wish they'd learned sooner. Harper Collins.

McKinsey \& Company. (2019, September). Automation and the future of work in Indonesia. https://www.mckinsey.com/featured-insights/asia-pacific/automation-and-the-futureof-work-in-indonesia

Neff, T.J. \& J.M. Citrin.(2001). Lesson from The Top. Doubleday Business.

Nye, C., Leong, F., Prasad, J., Gardner, D., \& Tien, H. (2017). Examining the Structure of the Career Adapt-Abilities Scale. Journal of Career Assessment, 26(3), 549-562. https://doi.org/10.1177/1069072717722767

Oktavita, F. (2014). Pengaruh Kepribadian Proaktif terhadap Kinerja Belajar pada Mahasiswa Akuntansi dengan Motivasi Belajar sebagai Variabel Intervening. Jurnal Ilmiah Mahasiswa Fakultas Ekonomi Dan Bisnis, 2(2). Retrieved 6 April 2020, from https://jimfeb.ub.ac.id/index.php/jimfeb/article/view/1011. 
Othman, R., Kamal, N., Alias, N., Ismail, S., \& Sahiq, A. (2018). Positive Psychological Traits and Career Adaptability among Millennials. International Journal of Academic Research in Business and Social Sciences, 8(9). http://dx.doi.org/10.6007/IJARBSS/v8-i9/4706

Preston, M. (2018). Pengarub Pola Asuh Ayah dan Ibu Terhadap Efikasi-Diri dalam Pengambilan Keputusan Karier yang Dimediasi oleh Kepribadian Proaktif pada Siswa Sekolah Menengah Atas [Tesis, Universitas Indonesia]. http://lontar.ui.ac.id/detail?id=20476219\&lokasi=lokal

Rezasyah, T., Darmawan, I. and Rifawan, A. (2019). Kesiapan Siswa SMK dalam Revolusi Industri 4.0. (Studi pada SMK Global Mulia Cikarang). Kumawula: Jumal Pengabdian Kepada Masyarakat, 1(2), p.114. https://doi.org/10.24198/kumawula.v1i2.20029

Reivich, K., \& Shatte, A. (2002). The resilience factor: 7 essential skills for overcoming life's inevitable obstacles. Broadway Books.

Rudolph, C., Lavigne, K., \& Zacher, H. (2017). Career adaptability: A meta-analysis of relationships with measures of adaptivity, adapting responses, and adaptation results. Journal of Vocational Behavior, 98, 17-34. https://doi.org/10.1016/i.jvb.2016.09.002

Ramdhani, R., \& Kiswanto, A. (2020). Urgensi Adaptabilitas dan Resiliensi Karier pada Masa Pandemi. Indonesian Journal of Educational Counseling, 4(2), 95-106. https://doi.org/10.30653/001.202042.135

Sagita, M. (2020, Desember 5). Hadapi Revolusi Industri 4.0, Apa yang Harus Disiapkan SMK?. Kumparan. https://kumparan.com/kumparannews/hadapi-revolusi-industri-4-0-apayang-harus-disiapkan-smk-1t3BGatSOVg/full

Savickas, M. (1997). Career Adaptability: An Integrative Construct for Life-Span, Life-Space Theory. The Career Development Quarterly, 45(3), 247-259. https://doi.org/10.1002/i.21610045.1997.tb00469.x

Savickas, M. L. (2005). The theory and practice of career construction. Dalam S. D. Brown \& R. W. Lent. (ed.) Career development and counseling: Putting theory and research to work (pp. 42-70). John Wiley \& Sons.

Savickas, M., Nota, L., Rossier, J., Dauwalder, J., Duarte, M., \& Guichard, J. et al. (2009). Life designing: A paradigm for career construction in the 21st century. Journal of Vocational Behavior, 75(3), 239-250. https://doi.org/10.1016/j.jvb.2009.04.004

Savickas, M., \& Porfeli, E. (2012). Career Adapt-Abilities Scale: Construction, reliability, and measurement equivalence across 13 countries. Journal of Vocational Behavior, 80(3), 661-673. https://doi.org/10.1016/j.jvb.2012.01.011

Santrock, J.W. (2012). Perkembangan Masa Hidup. Edisi ketigabelas. Jilid 1. Erlangga

Salisu, I., \& Hashim, N. (2017). A Critical Review of Scales Used in Resilience Research. IOSR Journal of Business snd Management, 19(04), 23-33. https://doi.org/10.9790/487X$\underline{1904032333}$

Shivanjali. (2010). Soft Skills Training Versus Hard Skills Training. International Journal In Multidisciplinary and Academic Research, 1(3).

Sutcliffe, K.M. \& Vogus, T.J. (2003). Organizing for resilience. Dalam Cameron, K.S., Dutton, J.E. and Quinn, R.E. (ed.), Positive Organizational Scholarship (pp. 94-110). Berrett-Koehler Publishers

Suthar, D. (2020). Linking Proactive Personality, Career Adaptability with Resilient to Career Shock: A 
Moderation of Support [Tesis, Tallinn University of Technology]. https://digikogu.taltech.ee/en/Download/8e0b28d6-8d75-48b3-8b58-8add96158247

Seibert, S. E., Crant, M. J., \& Kraimer, M. L. (1999). Proactive personality and career success. Journal of Appiied Psychology, 84 (3), 416-427. https://doi.org/10.1037/0021-9010.84.3.416

Sharf, R. S. (2006). Applying Career Development Theory of Counseling. Thomson Wadsworth.

Soresi, S., Nota, L., \& Ferrari, L. (2012). Career Adapt-Abilities Scale-Italian form: Psychometric properties and relationships to breadth of interests, quality of life, and perceived barriers. Journal of Vocational Behavior, 80(3), 705-711. https://doi.org/10.1016/i.jvb.2012.01.020

Tamannaeifar, M., \& Shahmirzaei, S. (2019). Prediction of Academic Resilience Based on Coping Styles and Personality Traits. Practice in Clinical Psychology, 7(1), 1-10. https://doi.org/10.32598/jpcp.7.1.1

The SMERU Research Institute. (2020, Juli 4). Mengantisipasi Potensi Dampak Krisis Akibat Pandemi COVID-19 terbadap Sektor Ketenagakerjaan. https://www.smeru.or.id/sites/default/files/publication/pb04 covidnaker in 0.pdf

Tolentino, L. R., Garcia, P. R. J. M., Lu, V. N., Restubog, S. L. D., Bordia, P., \& Plewa, C. (2014). Career adaptation: The relation of adaptability to goal orientation, proactive personality, and career optimism. Journal of Vocational Behavior, 84, 39-48. https://doi.org/10.1016/j.jvb.2013.11.004

Ulfah, F., \& Akmal, S. (2019). Peran Kepribadian Proaktif terhadap Adaptabilitas Karier pada Mahasiswa Tingkat Akhir. INTUISI: Jurnal Psikologi Ilmiah, 11(1). https://doi.org/2541$\underline{2965}$

Wu L, Tan Y, \& Liu Y (2017). Factor structure and psychometric evaluation of the ConnorDavidson Resilience Scale in a new employee population of China. BMC Psychiatry, 17, 1-7. https://doi.org/10.1186/s12888-017-1219-0 